\title{
Optimizing Technology Selection for Power Smart Grid Systems: a Case Study of Iran Power Distribution Industry (IPDI)
}

\author{
Maral Mohaghegh Montazeri ${ }^{1} \cdot$ Mohammad Najjartabar-Bisheh $^{2}$
}

Received: 24 June 2016 / Accepted: 16 March 2017 / Published online: 30 March 2017

(c) Springer Science+Business Media Singapore 2017

\begin{abstract}
The power smart grid (PSG) as a well-established research area is recently dealing with a wider range of topics such as power systems, energy generation and telecommunication. Selecting proper technologies for PSG systems is a complicated and multi-criteria decision making process. The present paper aims to identify the most important technologies for PSG at IPDI using a multi-criteria decision making (MCDM) technique, simple additive weighting (SAW). To this purpose, competent and knowledgeable decision makers in the field of PSG technologies were requested to evaluate the PSG technologies and its affiliated criteria and comment on them. They were also asked to rate each technology based on criteria set within the framework of SAW. The six-step algorithm of SAW has successfully identified moment billing, wireless technology and load forecasting as the most important technologies for PSG. This study suggests that both potential PSG technologies and criteria should be taken into account to optimize selecting important technologies.
\end{abstract}

Keywords Technology selection - Power distribution . Smart grid · Saw

Mohammad Najjartabar-Bisheh

Mnajjartabar@aut.ac.ir

Maral Mohaghegh Montazeri

Maral_mohaghegh@yahoo.com

1 Mazandaran University of Science and Technology, Babol, Iran

2 Department of Industrial and System Engineering, Amirkabir University of Technology, Hafez Ave, Tehran, 15875-4413, Iran

\section{Introduction}

Smart Grids (SGs) are regarded as the next generation of conventional grids because of its two-way power and information flow capabilities [1]. Smart Grids which are popular for their high security, self-healing features have many applications such as enabling a low carbon economy, decreasing electricity consumption, growing the electricity market, reducing the costs and production of peak load times, managing demand response and increasing application of renewable energy [2-4]. A Smart Grid refers to an entire electric system including generation, transmission, and distribution. Power distribution refers to the interface between the transmission system and consumers and the last part of a system which is responsible for delivering electrical energy to the consumers. Most power outages and disruptions occur in this area; therefore moving towards smart distribution system must begin from the bottom of the chain.

Technology selection is a complex decision activity that needs to be carried out properly otherwise a wrong selection may threaten an organization's well-being [5]. As the selection is commonly based on the subjective judgment of the decision makers, the experience and knowledge of the decision team members play a key role in not only in the evaluation but also in the selection of the technology. This multifaceted task requires the evaluation of different alternative options which are available for a set of conflicting criteria and process requirements [6]. The technology selection literature is particularly attentive to decision models that depend on experts' opinions, where a trade-off based on the weighted criteria determines a relative ranking.

Optimizing technology selection is reinforced by variety of fctors such as the necessity of using smart grids, 
the emerging knowledge of power smart grids (PSGs) for reducing the time of acquiring technologies, prioritizing investment in this section.

Nowadays, many technological alternatives, ranging from advanced to conventional, for PSG implementation are available. However, selecting the most appropriate technologies from a set of available alternatives is difficult. Sustainability criteria must be incorporated into the decision-making process. This implies that selecting the most important technologies is not a straight forward task. There are number of sustainability criteria which need to be taken into account [7]. This paper is an attempt to identify the most important technologies for Iran Power Distribution Institute (IPDI) using the MCDM technique, Simple Additive Weighting (SAW). The importance of this methodology lies in determining the direction of R\&D activities, adopting new technologies and developing the existing ones. The rest of this paper is organized as follows. "Literature review" presents a literature review; "SAW Algorithm" presents the mathematical model of SAW. In "A Case study of Iran Power Distribution Industry", implementation of SAW to the case of IPDI is presented. A conclusion is discussed in "Conclusion".

\section{Literature review}

The applications of various Multi Criteria Decision Making (MCDM) techniques in selecting technologies have been widely discussed in the literature. Ghiani \& Vertuccio presented an optimal sizing and operation strategy for a smart Microgrid equipped with renewable/non-renewable generators and storage. Technical and economic analyses were carried out by means of Hybrid Optimization Models for Energy Resources (HOMER) software which allows exploring several designs and operation alternatives [8]. In their paper, Li and Lao investigated different critical criteria predicting the success of the future intelligent power grid systems, and then developed MCDM models to identify the most suitable directions under rapidly-changing technological movements and market demands in complex social-economic environments. After a practical investigation, they realized that a centralised power grid system with grid -aware networks, cloud-computing and multi-purpose grid applications is more suitable for China's future development [9]. In another study, Guo and Zhao employed an MCDM technique to include some subjective but important criteria for Electric Vehicle Charging Station (EVCS) site selection. To modify the ambiguity and vagueness of the subjective judgments made by decision makers, fuzzy TOPSIS (The Technique for Order of Preference by Similarity to Ideal Solution) method was applied to select the optimal EVCS site. The evaluation index system for EVCS site selection was built based on a sustainability perspective, which consists of environmental, economic and social criteria associated with a total of 11 sub-criteria [10]. Ren and Lützen described the application of MCDM for the technology selection in emission reduction from shipping under uncertainties using incomplete information. Nine criteria in four aspects, including technological, economic, environmental and social-political aspects were used for the sustainability assessment. Fuzzy AHP was used to determine the weights of the evaluation criteria and the relative performance of the alternatives with respect to each evaluation criterion, and VIKOR was used to prioritize the alternative technologies [11]. Van de Kaa \&Rezaei focused on some standards battles for photovoltaic technological systems. Based on the literature and interviews conducted with experts, they developed different categories and factors determining the technology dominance of these systems. By applying the analytic hierarchy process, they determined the importance of these factors and assessed the chance of each technology for being a dominant photovoltaic technology [12]. Bottero and his associates used AHP and ANP on different wastewater treatment system. Multi-criteria analyses were carried out to make comparative assessments of alternatives projects or heterogeneous measures and include several criteria in a complex situation [13].

A careful perusal of literature shows that MCDM techniques that have been widely -used in technology selection. Simple additive weighting (SAW) is one of the techniques using a linear combination of matrices to compute a weight of alternative.. However, technology selections for smart grids have received less attention in the literature. Therefore, the aim of this paper is to select an appropriate technology for PGs using SAW.

\section{SAW Algorithm}

The proposed methodology includes 5 steps. Each step is discussed in detail:

Step 1) Identifying the list of technologies based on the articles and documents in the field of PSG.

Step 2) Selecting some criteria based on library research and interviews with the team of experts In developing criteria for technologies, we included economical, environmental, technological features of them.

Step 3) Developing a questionnaire for a group of decision makers.

In order to determine the weight of each criterion, decision makers were asked to express the priority of each criterion relative to others by couple matrixes in Table 1 
Table 1 Scoring is based on paired comparisons

\begin{tabular}{llll}
\hline Numerical value & $\begin{array}{l}\text { The degree of importance } \\
\text { in two by two comparison }\end{array}$ & Numerical value & $\begin{array}{l}\text { The degree of importance } \\
\text { in two by two comparison }\end{array}$ \\
\hline 1 & The same preference & 1 & The same preference \\
2 & Relatively preferable & $1 / 2$ & Much low importance \\
3 & Strongly preferable & $1 / 3$ & low importance \\
4 & Very strongly preferable & $1 / 4$ & Unimportant \\
5 & Quite preferable & $1 / 5$ & Quite unimportant \\
\hline
\end{tabular}

The geometrical average was used to merge their opinions (1) about the weight of the criteria was found.

$\mathrm{W}_{\mathrm{j}}=\sqrt[n]{\mathrm{W}_{\mathrm{j}}^{1} * \mathrm{~W}_{\mathrm{j}}^{2} * \ldots \ldots * \mathrm{~W}_{\mathrm{j}}^{\mathrm{k}}} \quad j=1,2, \ldots n$

$\mathrm{W}_{\mathrm{j}}^{\mathrm{k}}$ is the normal weight of $\mathrm{j}$-th criteria of $\mathrm{k}$-th decision maker and $\widetilde{W}_{j}$ is the weight special vector that obtained from dividing of geometrical average of that row to the geometrical average of rows.

Step 4) Asking experts to rate their opinions on alternatives with respect to each criterion. The structured

Table 2 List of PSG technologies

\begin{tabular}{ll}
\hline & Technology \\
\hline $\mathrm{T}_{1}$ & DER dispatch capability \\
$\mathrm{T}_{2}$ & Power flow rearrangement \\
$\mathrm{T}_{3}$ & Micro grid \\
$\mathrm{T}_{4}$ & Renewable production resources \\
$\mathrm{T}_{5}$ & Energy storage resource \\
$\mathrm{T}_{6}$ & Control equipment \\
$\mathrm{T}_{7}$ & Measurement equipment \\
$\mathrm{T}_{8}$ & Communication management \\
$\mathrm{T}_{9}$ & Wired technology \\
$\mathrm{T}_{10}$ & Wireless technology \\
$\mathrm{T}_{11}$ & Software \\
$\mathrm{T}_{12}$ & Information storing \\
$\mathrm{T}_{13}$ & Information management \\
$\mathrm{T}_{14}$ & Load losses \\
$\mathrm{T}_{15}$ & Network losses \\
$\mathrm{T}_{16}$ & Activities for system restore \\
$\mathrm{T}_{17}$ & Estimate staff needed to resolve outages \\
$\mathrm{T}_{18}$ & Estimate the approximate recovery time \\
$\mathrm{T}_{19}$ & Outages locating \\
$\mathrm{T}_{20}$ & Load forecasting \\
$\mathrm{T}_{21}$ & Customer information system \\
$\mathrm{T}_{22}$ & Moment billing \\
$\mathrm{T}_{23}$ & Energy costs calculating \\
$\mathrm{T}_{24}$ & Energy storage resource management \\
$\mathrm{T}_{25}$ & Renewable production management \\
$\mathrm{T}_{26}$ & Conventional production management \\
\hline &
\end{tabular}

questionnaire consisted of the identified criteria and its corresponding alternatives. Therefore, the priority given to the technologies in criteria 1 to $\mathrm{n}$ was calculated respectively using Eqs. 2 and 3.

$$
\begin{aligned}
\mathrm{X}_{\mathrm{ij}} & =\sqrt[n]{\mathrm{X}_{\mathrm{ij}}^{1} * \mathrm{X}_{\mathrm{ij}}^{2} * \ldots \ldots * \mathrm{X}_{\mathrm{ij}}^{\mathrm{k}}} \quad \mathrm{j}=1,2, \ldots, \mathrm{n} \\
\mathrm{i} & =1,2, \ldots, \mathrm{m}
\end{aligned}
$$

$\mathrm{X}_{\mathrm{ij}}^{\mathrm{k}}$ is the status of $\mathrm{i}$-th technology in the $\mathrm{j}$-th criteria with the point of k-th decision maker and $\mathrm{X}_{\mathrm{ij}}$ is the status of each technology in each criterion.

Step 5) Decision matrix was defined as follows:

$$
\begin{aligned}
& \mathrm{D}=\left|\begin{array}{rrrr}
\mathrm{X}_{11} & \mathrm{X}_{12} & \ldots \ldots & \mathrm{X}_{1 \mathrm{n}} \\
\mathrm{X}_{21} & \mathrm{X}_{22} & \ldots \ldots & \mathrm{X}_{2 \mathrm{n}} \\
\vdots & \vdots & \vdots & \vdots \\
\mathrm{X}_{\mathrm{m} 1} & \mathrm{X}_{\mathrm{m} 2} & \ldots \ldots & \mathrm{mn}
\end{array}\right| \\
& \mathrm{j}=1,2, \ldots \ldots, \mathrm{n} \\
& \mathrm{j}=1,2, \ldots \ldots, \mathrm{m}
\end{aligned}
$$

\begin{tabular}{|c|c|c|}
\hline No & Criteria & Weight \\
\hline $\mathrm{C}_{1}$ & $\begin{array}{l}\text { The cost of acquiring technical } \\
\text { knowledge and localizing technology }\end{array}$ & 0.095 \\
\hline $\mathrm{C}_{2}$ & $\begin{array}{l}\text { The added value related } \\
\text { to the technology development }\end{array}$ & 0.08 \\
\hline $\mathrm{C}_{3}$ & $\begin{array}{l}\text { The possibility of exporting technology } \\
\text { after having a full access to it }\end{array}$ & 0.053 \\
\hline $\mathrm{C}_{4}$ & The urgency of having - technology & 0.099 \\
\hline $\mathrm{C}_{5}$ & $\begin{array}{l}\text { Developing and improving the quality } \\
\text { of electricity services }\end{array}$ & 0.168 \\
\hline $\mathrm{C}_{6}$ & $\begin{array}{l}\text { The amount of investment } \\
\text { required for technology }\end{array}$ & 0.142 \\
\hline $\mathrm{C}_{7}$ & $\begin{array}{l}\text { Power industry support for } \\
\text { technology development }\end{array}$ & 0.142 \\
\hline $\mathrm{C}_{8}$ & The future needs of Technology & 0.142 \\
\hline $\mathrm{C}_{9}$ & $\begin{array}{l}\text { The risk of technology replacement } \\
\text { with newer technology }\end{array}$ & 0.079 \\
\hline
\end{tabular}

Where $X_{\mathrm{ij}}^{\mathrm{k}}$ was obtained from Eq. 2.

Table 3 Weight of criteria 
Table 4 Normalize decision matrix (R)

\begin{tabular}{lllllllll}
\hline 0.102 & 0.151 & 0.091 & 0.11 & 0.129 & 0.101 & 0.084 & 0.131 & 0.101 \\
0.105 & 0.109 & 0.098 & 0.115 & 0.112 & 0.099 & 0.121 & 0.127 & 0.114 \\
0.097 & 0.112 & 0.134 & 0.125 & 0.115 & 0.113 & 0.07 & 0.139 & 0.095 \\
0.131 & 0.113 & 0.099 & 0.095 & 0.098 & 0.102 & 0.131 & 0.126 & 0.105 \\
0.089 & 0.101 & 0.091 & 0.148 & 0.131 & 0.125 & 0.077 & 0.128 & 0.11 \\
0.112 & 0.104 & 0.109 & 0.121 & 0.126 & 0.108 & 0.081 & 0.126 & 0.113 \\
0.114 & 0.089 & 0.122 & 0.113 & 0.124 & 0.101 & 0.088 & 0.128 & 0.121 \\
0.102 & 0.105 & 0.096 & 0.132 & 0.099 & 0.106 & 0.103 & 0.149 & 0.108 \\
0.123 & 0.109 & 0.108 & 0.119 & 0.131 & 0.088 & 0.092 & 0.097 & 0.133 \\
0.102 & 0.121 & 0.077 & 0.111 & 0.116 & 0.109 & 0.116 & 0.123 & 0.122 \\
0.108 & 0.139 & 0.123 & 0.112 & 0.118 & 0.084 & 0.066 & 0.138 & 0.112 \\
0.108 & 0.111 & 0.098 & 0.119 & 0.125 & 0.085 & 0.093 & 0.137 & 0.124 \\
0.109 & 0.102 & 0.102 & 0.104 & 0.138 & 0.082 & 0.103 & 0.159 & 0.101 \\
0.106 & 0.121 & 0.077 & 0.121 & 0.105 & 0.109 & 0.116 & 0.101 & 0.122 \\
0.096 & 0.122 & 0.097 & 0.111 & 0.103 & 0.119 & 0.091 & 0.142 & 0.119 \\
0.118 & 0.112 & 0.089 & 0.123 & 0.133 & 0.103 & 0.092 & 0.116 & 0.114 \\
0.133 & 0.105 & 0.085 & 0.149 & 0.104 & 0.097 & 0.086 & 0.121 & 0.12 \\
0.118 & 0.102 & 0.095 & 0.129 & 0.134 & 0.081 & 0.104 & 0.138 & 0.099 \\
0.091 & 0.125 & 0.084 & 0.101 & 0.129 & 0.108 & 0.111 & 0.129 & 0.122 \\
0.117 & 0.118 & 0.107 & 0.103 & 0.119 & 0.115 & 0.116 & 0.118 & 0.087 \\
0.108 & 0.099 & 0.089 & 0.107 & 0.128 & 0.097 & 0.112 & 0.154 & 0.106 \\
0.144 & 0.102 & 0.104 & 0.094 & 0.109 & 0.107 & 0.136 & 0.106 & 0.098 \\
0.137 & 0.133 & 0.109 & 0.084 & 0.098 & 0.095 & 0.142 & 0.106 & 0.096 \\
0.116 & 0.112 & 0.108 & 0.129 & 0.113 & 0.106 & 0.088 & 0.127 & 0.101 \\
0.124 & 0.081 & 0.089 & 0.142 & 0.117 & 0.118 & 0.108 & 0.087 & 0.134 \\
0.107 & 0.136 & 0.105 & 0.119 & 0.107 & 0.098 & 0.087 & 0.117 & 0.124 \\
\hline
\end{tabular}

To create compatibility between the qualitative criteria and subjective criteria ratings, different scales can be changed to one scale using a linear scale. Normalize decision matrix that shown with R, was obtained using Eq. 3 .

$$
\mathrm{R}=\left[\mathrm{r}_{\mathrm{ij}}\right] \mathrm{m} \times \mathrm{n} \quad \mathrm{r}_{\mathrm{ij}}=\frac{\mathrm{X}_{\mathrm{ij}}}{\sum_{\mathrm{j}=1}^{\mathrm{n}} \mathrm{X}_{\mathrm{ij}}}
$$

Step 6) Considering the importance of the criteria by calculating the final value of any technology $(\mathrm{Pi})$ using the following formula:

$$
\mathrm{P}_{\mathrm{i}}=\sum_{j=1}^{n} r_{i j} \tilde{W}_{j} \quad i=1,2, \ldots, \mathrm{m}
$$

With the identified final value of technologies in the PSG, Prioritization of these technologies based on the evaluation criteria was determined to address the organization's objectives.

\section{A Case Study of Iran Power Distribution Industry}

Apart from the many benefits of smart grid systems and hierarchical construction of power networks in Iran, there are variety of reasons that justify using smart grids and their localization. These factors are the unfeasibility of extending
Table 5 Final value of the IPSI technologies

\begin{tabular}{llllllll}
\hline $\mathrm{P}_{\mathrm{i}}$ & $\sum_{j=1}^{n} r_{i j} \tilde{W}_{j}$ & $\mathrm{P}_{\mathrm{i}}$ & $\sum_{j=1}^{n} r_{i j} \tilde{W}_{j}$ & $\mathrm{P}_{\mathrm{i}}$ & $\sum_{j=1}^{n} r_{i j} \tilde{W}_{j}$ & $\mathrm{P}_{\mathrm{i}}$ & $\sum_{j=1}^{n} r_{i j} \tilde{W}_{j}$ \\
\hline $\mathrm{P}_{1}$ & 0.1123 & $\mathrm{P}_{8}$ & 0.111 & $\mathrm{P}_{15}$ & 0.1115 & $\mathrm{P}_{22}$ & 0.1149 \\
$\mathrm{P}_{2}$ & 0.1102 & $\mathrm{P}_{9}$ & 0.1122 & $\mathrm{P}_{16}$ & 0.1118 & $\mathrm{P}_{23}$ & 0.1135 \\
$\mathrm{P}_{3}$ & 0.1087 & $\mathrm{P}_{10}$ & 0.1142 & $\mathrm{P}_{17}$ & 0.1125 & $\mathrm{P}_{24}$ & 0.1105 \\
$\mathrm{P}_{4}$ & 0.1108 & $\mathrm{P}_{11}$ & 0.1134 & $\mathrm{P}_{18}$ & 0.1104 & $\mathrm{P}_{25}$ & 0.1111 \\
$\mathrm{P}_{5}$ & 0.1117 & $\mathrm{P}_{12}$ & 0.1085 & $\mathrm{P}_{19}$ & 0.1133 & $\mathrm{P}_{26}$ & 0.109 \\
$\mathrm{P}_{6}$ & 0.1125 & $\mathrm{P}_{13}$ & 0.1116 & $\mathrm{P}_{20}$ & 0.1138 & & \\
$\mathrm{P}_{7}$ & 0.1115 & $\mathrm{P}_{14}$ & 0.1097 & $\mathrm{P}_{21}$ & 0.1128 & & \\
\hline
\end{tabular}


transmission lines, the potential use of renewable energies like wind and solar, numerous unexpected events, relatively high population density, the desire for reducing and managing costs, and the potential use of electric vehicles in the region. These factors highlight the necessity of identifying the most important technologies and focusing on them. This section explains how a decision for selecting proper PSG technologies should be made adopting SAW. Following a thorough search on technologies for PSG, we identified a list of PSG technologies. The technologies are presented in Table 2.

\section{Data Analysis}

We developed a questionnaire based on the identified twenty-six key technologies and nine criteria. The questionnaire was sent to some experts at power distribution industry such as Niroo Research Institute of Iran, Monenco Iran Consulting Engineers Company, Iran Energy Efficiency of Iran and expert at some universities such as Power and Water University of Technology and Mazandaran University of science and Technology. 15 questionnaires were sent back. and decision makers were requested to evaluate the available data $(m=26, n=9)$. Using the Eq. 1 , the weight of each criterion was calculated (see Table 3). Decision makers' opinions about 26 technologies on each criterion were rated on the scale ranging from 1 to 9 . Decision matrix was developed using the Eqs. 2 and 3, then the normal matrix was calculated using the Eq. 4 (see Table 4).

Finally, using equation (8), the final value of the PSG technologies was calculated and Prioritization of the technologies was identified. The results are shown in Table 5.

\section{Finding and Discussion}

Looking at the numbers in Table 5, we can see that PSG technologies which were prioritized for the case of IPDI are based on the following criteria (listed numbers show the number of key technologies in Table 2):

$$
\begin{aligned}
22 & >10>20>23>11>19>21>6>1>16>5>13>15 \\
& =7>25>8>4>18>24>2>14>26>3>12>17
\end{aligned}
$$

The first 5 identified criteria for determining the direction of R \& D activities for PSG are: moment billing, wireless, forecasting load, calculating energy costs and software technologies and technical knowledge. In addition, knowledge about outages location, CIS, control equipment, power dispatch and wired technology are placed in the second priority. The results reveal that load management is in the attention of power industry. In the other word, it is essentially important to plan technologies considering energy consumption.

\section{Conclusion}

Nowadays, the power industry as a strategic industry has gained the attention of the researchers. Adopting PSG, identifying $\mathrm{R} \& \mathrm{D}$ activities, employing new technologies and making decisions about them are the reasons that justify the evaluation of technologies. In this study, we sought to choose the most important PSG technologies in IPDI. In this regard, by reviewing the previous research, the SAW model was used for the technology selection. Following six steps, we identified 26 technologies and 9 criteria. To calculate the weight of criteria and to prioritize technologies, the questionnaire was given to the experts. Results showed that moment billing, wireless and forecasting loads are the important technologies. Considering these three technologies may result in load balancing, increasing productivity, reducing costs and creating a balance between demand and supply of electric energy. Unfortunately, many problems such as power cut and voltage drop exist in the electricity distribution sector of Iran due to non-engineering designs and lack of foresight. The failure of notifying the subscribers about the electricity prices during the peak demand at any moment may increase both consumption and the costs. A suitable way of information sharing and communication about the implementation of smart grids can lead to a lower cost and an optimal technical result. Such a result may be achieved by balancing the electricity flow between distribution and demand. Finally, using wireless technology and forecasting the load can save the cost and the time of installation and result in a more accurate prediction about load and a better investment and better planning in developing power plants and distribution networks.

\section{References}

1. Colak I, Kabalci E, Fulli G, Lazarou S (2015) A survey on the contributions of power electronics to smart grid systems. Renew Sust Energ Rev 47:562-579

2. Biabani M, Golkar MA, Kasiry AHZ, Akbari M (2011) Smart grid in Iran: Driving factors, evolution, challenges and possible solutions. In: 2011 10th international conference on environment and electrical engineering (EEEIC). IEEE, pp 1-4

3. El-Hawary ME (2014) The Smart Grid-State-of-the-art and Future Trends. Electr Power Compon Syst 42(3-4):239-250

4. Fang X, Misra S, Xue G, Yang D (2012) Smart grid-The new and improved power grid: A survey. IEEE Commun Surv Tutorials 14(4):944-980

5. Garcia JL, Alvarado A (2012) Problems in the implementation process of advanced manufacturing technologies. The International Journal of Advanced Manufacturing Technology

6. Evans L, Lohse N, Summers M (2013) A fuzzy-decisiontree approach for manufacturing technology selection exploiting experience-based information. Expert Syst Appl 40(16): 6412-6426

7. Bottero M, Comino E, Riggio V (2011) Application of the analytic hierarchy process and the analytic network process for the 
assessment of different wastewater treatment systems. Environ Model Softw 26(10):1211-1224

8. Ghiani E, Vertuccio C, Pilo F (2015) Optimal sizing and management of a smart Microgrid for prevailing self-consumption. In: PowerTech, 2015 IEEE Eindhoven. IEEE, pp 1-6

9. Li KZ, Lao LL, Guo YQ (2015) Future Directions for Smart Grid: A Conceptual Model. In: 2015 International conference on management engineering and management innovation (icmemi-15). Atlantis Press

10. Guo S, Zhao H (2015) Optimal site selection of electric vehicle charging station by using fuzzy TOPSIS based on sustainability perspective. Appl Energy 158:390-402
11. Ren J, Lützen M (2015) Fuzzy multi-criteria decision-making method for technology selection for emissions reduction from shipping under uncertainties. Transp Res Part D: Transp Environ 40:43-60

12. van de Kaa G, Rezaei J, Kamp L, de Winter A (2014) Photovoltaic technology selection: A fuzzy MCDM approach. Renew Sust Energ Rev 32:662-670

13. Bottero M, Comino E, Riggio V (2011) Application of the analytic hierarchy process and the analytic network process for the assessment of different wastewater treatment systems. Environ Model Softw 26(10):1211-1224 